\title{
A Novel Pathway for Hormonally Active Calcitriol
}

\author{
Bodo Lehmann Peter Knuschke Michael Meurer \\ Department of Dermatology, Carl Gustav Carus Medical School, Dresden University of Technology, \\ Dresden, Germany
}

\section{Key Words}

Calcitriol · Keratinocyte · Microdialysis · UVB •

Vitamin $D_{3}$

\begin{abstract}
Calcitriol $\left[1 \alpha, 25(\mathrm{OH})_{2} \mathrm{D}_{3}\right]$, the hormonally active form of vitamin $D_{3}\left(D_{3}\right)$ is produced in both renal and extrarenal tissues. Our findings demonstrate that physiological doses of UVB radiation at $300 \mathrm{~nm}$ induce the conversion of 7-dehydrocholesterol (7-DHC) via $\operatorname{preD}_{3}$ and $\mathrm{D}_{3}$ into calcitriol in the pmol range in epidermal keratinocytes. The hydroxylation of photosynthesized $D_{3}$ to calcitriol is strongly suppressed by ketoconazole, a known inhibitor of cytochrome P450 mixed function oxidases. The UVBinduced formation of calcitriol in human skin is demonstrable in vivo by the microdialysis technique. These results suggest that human skin is an autonomous source of hormonally active calcitriol.
\end{abstract}

Copyright @ 2001 S. Karger AG, Basel

\section{Introduction}

Cutaneous vitamin $\mathrm{D}_{3}\left(\mathrm{D}_{3}\right)$ is generated by UVBinduced photolysis of 7-dehydrocholesterol (7-DHC) [1]. Once formed, $\mathrm{D}_{3}$ is transported to the liver [2, 3] where it is metabolized to calcidiol $\left(25 \mathrm{OHD}_{3}\right)$ which is

\section{KARGER}

Fax +41613061234 E-Mail karger@karger.ch www.karger.com
(C) 2001 S. Karger AG, Basel

0301-0163/00/0546-0312\$17.50/0

Accessible online at:

www. karger.com/journals/hre further metabolized in the kidney [4, 5] to calcitriol $\left[1 \alpha, 25(\mathrm{OH})_{2} \mathrm{D}_{3}\right]$, the hormonal active form of $\mathrm{D}_{3}$. Except from its calcitropic action, $1 \alpha, 25(\mathrm{OH})_{2} \mathrm{D}_{3}$ has antiproliferative and prodifferentiative effects on epidermal keratinocytes [6-8]. However, the calcitriol concentration required to suppress growth of keratinocytes in vitro are substantially higher than present in blood [6]. On the other hand, it has been shown that cultured keratinocytes can convert exogeneous calcidiol $\left(25 \mathrm{OHD}_{3}\right)$ to calcitriol [9]. The physiological importance of this pathway however is unclear because only trace amounts of calcitriol were synthesized from calcidiol by skin ex vivo [10]. Previously, we were able to demonstrate that in cultures of human keratinocytes biologically inactive $\mathrm{D}_{3}$ can be converted to $1 \alpha, 25(\mathrm{OH})_{2} \mathrm{D}_{3}[11,12]$. Since the skin is both the site of $\mathrm{D}_{3}$ synthesis and a target organ for $1 \alpha, 25(\mathrm{OH})_{2} \mathrm{D}_{3}$ it is important to know whether UVB-induced photolysis of 7-DHC with consecutive synthesis of $\mathrm{D}_{3}$ can influence the epidermal production $1 \alpha, 25(\mathrm{OH})_{2} \mathrm{D}_{3}$.

\section{Methods}

\section{Cell Culture}

$\mathrm{HaCaT}$ cells (used with the permission of Prof. N.E. Fusenig of the German Cancer Research Center, Heidelberg) were seeded at a density of $5 \times 10^{4}$ cells $/ \mathrm{cm}^{2}$ in culture dishes $(\varnothing 30 \mathrm{~mm})$ and grown in DMEM supplemented with 5\% (v/v) FCS. Cultures were maintained at $37^{\circ} \mathrm{C}$ and $5 \% \mathrm{CO}_{2}$ in air. After synchronization the

Bodo Lehmann, Department of Dermatology

Carl Gustav Carus Medical School, Dresden University of Technology

Fetscherstrasse 74, D-01307 Dresden (Germany)

Tel. +49 3514582692 , Fax +49 3514584338

E-Mail Bodo.lehmann@mailbox.tu-dresden.de 
medium was replaced by serum-free DMEM supplemented with $1.0 \%(\mathrm{w} / \mathrm{v})$ of highly purified BSA (Sigma). At this time cells were preconfluent (equal to $\approx 0.7 \times 10^{6} \mathrm{cells} / \mathrm{dish}$ ). Cell numbers and their viability were assessed using a CASY ${ }^{\circledR} 1$ cell counter (Schärfe System $\mathrm{GmbH}$, Reutlingen, Germany). The viability was always $\geq 93 \%$.

\section{Incubation Conditions}

7-DHC (final concentration: $25 \mu M, 30 \mathrm{nmol} /$ dish) dissolved in ethanol (final concentration: $0.83 \%(\mathrm{v} / \mathrm{v})$ ), was added to the cultures. Control experiments were carried out: (1) with cultures in presence of 7-DHC without irradiation; (2) solvent alone with and without irradiation; (3) medium containing 7-DHC in absence of cells with irradiation. Irradiation was followed by $16 \mathrm{~h}$ incubation in dark. The medium and detached cells were extracted with methanol:chloroform (1:1). In the chloroform phase pre- $\mathrm{D}_{3}, \mathrm{D}_{3}, 7-\mathrm{DHC}$ and $1 \alpha, 25(\mathrm{OH})_{2} \mathrm{D}_{3}$ were determined.

\section{UV Irradiation}

Monochromatic light (bandwidth $5 \mathrm{~nm}$ ) was generated by a Dermolum HI monochromator (1-kVA Xe lamp, Müller, Germany). The distance between light source and the bottom of open culture dish $(\varnothing 30 \mathrm{~mm}$ ) was $14 \mathrm{~mm}$. The beam had a diameter of $15 \mathrm{~mm}$. The culture dish was continously turned during irradiation and the beam was positioned at the radius of the rotating dish. The UVB doses used were adapted to these experimental conditions (effective dose $=\mathrm{D}_{\text {eff }}$ $=$ calculated dose $\times 0.25$ ). Irradiances were measured with a calibrated thermopile.

\section{HPLC Analysis}

NP-HPLC. Merck/Hitachi; column: LiChroCART 250-4, Superspher Si 60, $5 \mu \mathrm{m}$; eluent 1 (n-hexane:2-propanol = 95:5 (v/v); flow rate: $0.5 \mathrm{ml} / \mathrm{min}$ ) for the determination of pre- $\mathrm{D}_{3}, \mathrm{D}_{3}$ and 7-DHC; eluent 2 (n-hexane:2-propanol:methanol = 87:10:3 (v/v/v); flow rate: $1.0 \mathrm{ml} / \mathrm{min}$ ) for fractionation of calcitriol (retention time: $21 \mathrm{~min}$ ). The peaks of pre- $\mathrm{D}_{3}, \mathrm{D}_{3}$ and 7-DHC (retention times: $8.20 \mathrm{~min}$, $10.56 \mathrm{~min}$ and $11.58 \mathrm{~min}$ respectively) were quantified by UV detection at $265 \mathrm{~nm}$. HPLC fractions containing calcitriol were collected and analyzed for calcitriol using a radioreceptor assay (Nichols Institute). The calcitriol generated was identified by co-chromatography of the ${ }^{3} \mathrm{H}$-labeled standard.

RP-HPLC. Rechromatography of calcitriol on a Hibar ${ }^{\odot}$ column, 250-4, LiChrospher 100RP-18, $5 \mu \mathrm{m}$ (Merck, Darmstadt, Germany); eluent: methanol:water $=85: 15(\mathrm{v} / \mathrm{v})$, flow rate: $1 \mathrm{ml} / \mathrm{min}$; retention time of synthetic $\left[{ }^{3} \mathrm{H}\right] 1 \alpha, 25(\mathrm{OH})_{2} \mathrm{D}_{3}: 10.0 \mathrm{~min}$.

\section{GC-MS Analysis}

Dried fractions from HPLC were derivatized to TMS ether derivatives and analyzed by GC-MS. The derivatized sample $(1 \mu \mathrm{l})$ was directly injected manually into a model 5890/II gas chromatograph equipped with a $25 \mathrm{~m} \times 0.2 \mathrm{~mm} \mathrm{HP}-1$ capillary column (cross-linked methylsiloxane, $0.33 \mu \mathrm{m}$ ) and interfaced with a model 5989A MS Engine (Hewlett-Packard, Palo Alto, CA, USA).

\section{Microdialysis}

Investigations were carried out during winter. The microdialysis probe used (CMA 70, CMA/Microdialysis Research AB, Sweden) has a shaft length of $60 \mathrm{~mm}$ and a membrane length of $10 \mathrm{~mm}$. The steel shaft of the probe has an outer diameter of $0.64 \mathrm{~mm}$. The diameter at the tip of the probe where the dialysis membrane is located is $0.5 \mathrm{~mm}$. The molecular weight cutoff point for the membrane is

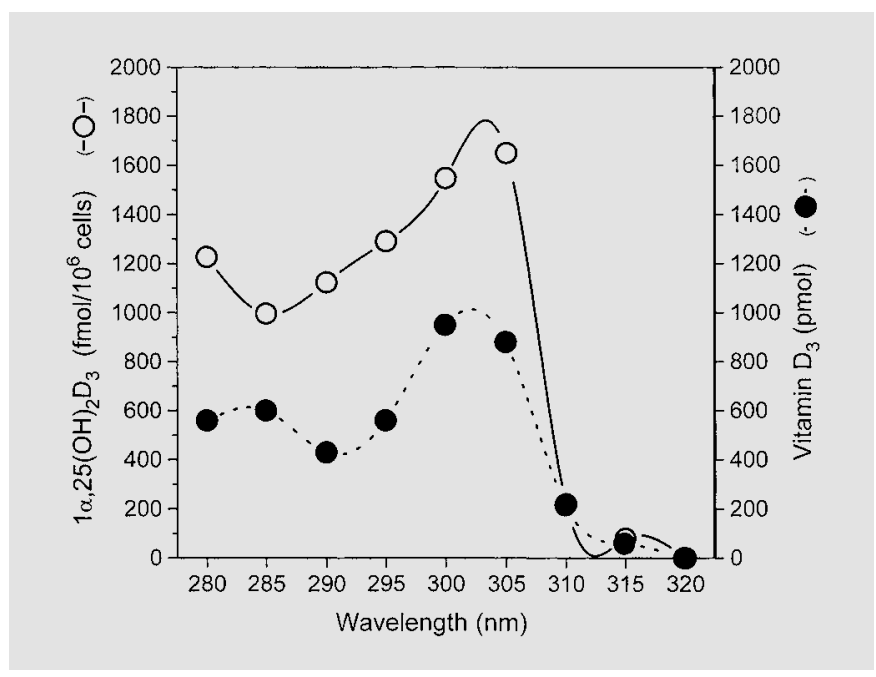

Fig. 1. Relationship between wavelengths of UVB light and the generation of $\mathrm{D}_{3}$ and $1 \alpha, 25(\mathrm{OH})_{2} \mathrm{D}_{3}$ in $\mathrm{HaCaT}$ cells. Cultures preincubated with $25 \mu M$ 7-DHC were irradiated at several wavelengths between $285 \mathrm{~nm}$ and $320 \mathrm{~nm}$ (dose: $30 \mathrm{~mJ} \times \mathrm{cm}^{-2}$ ) followed by $16 \mathrm{~h}$ incubation. Each point represents the mean of two independent experiments.

$20 \mathrm{kD}$. The abdomen was selected as site for insertion of two independent microdialysis probes (UVB irradiation and control, respectively). When local anesthesia at the point of insertion was done, an apheresis needle $(1.60 \times 32 \mathrm{~mm})$ was inserted as a guide, as superficially as possible for $15 \mathrm{~mm}$. The probe was inserted through the guide, which was then withdrawn and taped in position. The site of insertion and the area above the tip of the probe were marked. The probe was first flushed with Ringer's solution using a CMA 107 microdialysis pump for $5 \mathrm{~min}$ at a flow rate of $15 \mu \mathrm{l} / \mathrm{min}$. Thereafter the flow was changed to $0.3 \mu \mathrm{l} / \mathrm{min}$, and the dialysate was fractionated into microvials for $3 \mathrm{~h}$ each (control). The second probe was uncovered after $3 \mathrm{~h}$ and irradiated wih monochromatic UVB at $300 \mathrm{~nm}$ (doses: 14 or $28 \mathrm{~mJ} \times \mathrm{cm}^{-2}$, equal to 0.7 or $1.4 \mathrm{MED}$, respectively). The microvials were changed every $3 \mathrm{~h}$ until $24 \mathrm{~h}$ after UVB exposure. The content of $1 \alpha, 25(\mathrm{OH})_{2} \mathrm{D}_{3}$ in $50 \mu$ dialysate of each fraction was determined by radioreceptor assay (see above).

\section{Results and Discussion}

In vitro experiments using the $\mathrm{HaCaT}$ cell line demonstrated the UVB-induced conversion of exogeneous 7-DHC via previtamin $\mathrm{D}_{3} \quad\left(\right.$ pre- $\left.\mathrm{D}_{3}\right)$ and $\mathrm{D}_{3}$ to $1 \alpha, 25(\mathrm{OH})_{2} \mathrm{D}_{3}$ in these cells. The rate of formation of $1 \alpha, 25(\mathrm{OH})_{2} \mathrm{D}_{3}$ in $\mathrm{HaCaT}$ cells depends on the UVB wavelength used for irradiation and is very similar to that of $\mathrm{D}_{3}$, showing maxima at around $303 \mathrm{~nm}$ (fig. 1). This finding points to a close relation between UVB-induced $\mathrm{D}_{3}$ synthesis and consecutive formation of $1 \alpha, 25(\mathrm{OH})_{2} \mathrm{D}_{3}$. 




Fig. 2. Inhibitory effect of ketoconazole and 1,2-dianilinoethane on hydroxylation of $\mathrm{D}_{3}$ created after irradiation with UVB to $1 \alpha, 25(\mathrm{OH})_{2} \mathrm{D}_{3}$ in $\mathrm{HaCaT}$ cells. Cultures containing $25 \mu M$ 7-DHC were irradiated at $300 \mathrm{~nm}$ (dose: $30 \mathrm{~mJ} \times \mathrm{cm}^{-2}$ ). Immediately after irradiation, ethanol (control), ketoconazole $(10 \mu M)$ or 1,2-dianilinoethane $(10 \mu M)$ were added to the cultures, and further incubation for $16 \mathrm{~h}$ at $37^{\circ} \mathrm{C}$ was done in the dark. Concentrations obtained are depicted as relative percent $\pm \mathrm{SD}$ of control $(100 \pm 8 \%$ equal to $1990 \pm 159$ fmol calcitriol) of three independent experiments. $* * * \mathrm{p}<0.001$ compared to control.

Calcitriol obtained after NP-HPLC (eluent 2) of extracts of irradiated HaCaT cells $\left(300 \mathrm{~nm}\right.$; dose: $30 \mathrm{~mJ} \times \mathrm{cm}^{-2}$; irradiance: $0.28 \mathrm{~mW} \times \mathrm{cm}^{-2}$ ) was identical with synthetic standard calcitriol as shown by co-migration with ${ }^{3} \mathrm{H}-$ $1 \alpha, 25(\mathrm{OH})_{2} \mathrm{D}_{3}$ in NP and RP-HPLC systems. No calcitriol was detectable in extracts of unirradiated $\mathrm{HaCaT}$ cells. Studies of the TMS derivatives of synthetic and generated calcitriol by GC-MS demonstrated identical retention times as well as full-scan EI mass spectra.

Ketoconazole [13] dose-dependently inhibited the UVB-induced generation of calcitriol in $\mathrm{HaCaT}$ cells when added to the culture immediately after irradiation (fig. 2). In contrast, the radical scavenger and antioxidant 1,2-dianilinoethane [14] showed only marginal inhibitory effects on the generation of $1 \alpha, 25(\mathrm{OH})_{2} \mathrm{D}_{3}$ (fig. 2). This finding points to an enzymatically catalyzed pathway of $\mathrm{D}_{3}$ to $1 \alpha, 25(\mathrm{OH})_{2} \mathrm{D}_{3}$ as previously found after exogenous addition of $\mathrm{D}_{3}$ to cultured keratinocytes $[11,12]$.

Calculations indicate that only $0.007 \%$ of the UVBirradiated 7-DHC (30 nmol/dish) is converted to $1 \alpha, 25(\mathrm{OH})_{2} \mathrm{D}_{3}$ (equal to $2.093 \mathrm{fmol} / 10^{6}$ cells). For comparison, the normal range of the concentration of $1 \alpha, 25(\mathrm{OH})_{2} \mathrm{D}_{3}$ in human serum is $68 \pm 27 \mathrm{fmol} / \mathrm{ml}[15]$.

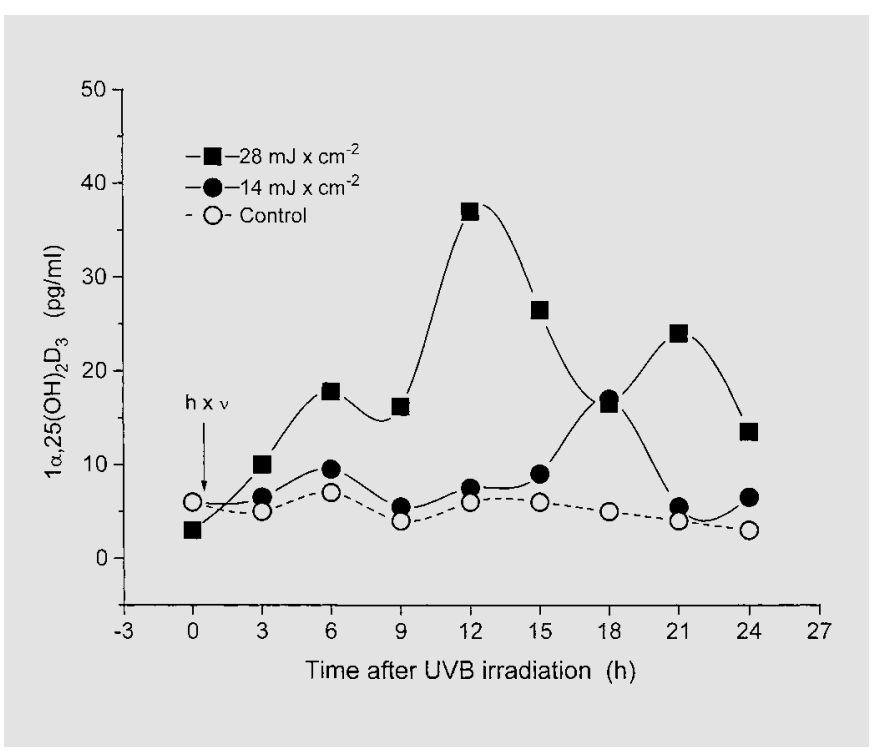

Fig. 3. Microdialysis probe for cutaneous monitoring of $1 \alpha, 25(\mathrm{OH})_{2} \mathrm{D}_{3}$ after UVB irradiation of human skin. Skin was irradiated at $300 \mathrm{~nm}$ at $14 \mathrm{~mJ} \times \mathrm{cm}^{-2}$ or $28 \mathrm{~mJ} \times \mathrm{cm}^{-2}$ (equal to 0.7 and 1.4 MED, respectively) and not irradiated (control). Flow rate of dialysis fluid: $0.3 \mu \mathrm{l} / \mathrm{min}$, volume of fraction: $54 \mu \mathrm{l} / 3 \mathrm{~h}$, total duration of microdialysis: $27 \mathrm{~h}$. Calcitriol was determined in $50 \mu \mathrm{l}$ dialysate. Data are depicted as mean values of two independent experiments.

Finally, we have been able to show in preliminary experiments that the UVB-induced formation of calcitriol at $300 \mathrm{~nm}$ in human skin can be demonstrated using the microdialysis technique (fig. 3). Calcitriol concentrations in the dialysate were at a maximum 12-18 $\mathrm{h}$ after UVB irradiation and increased with rising UVB doses up to $28 \mathrm{~mJ} \times \mathrm{cm}^{-2}$ (equal to $1.4 \mathrm{MED}$ ).

It can be concluded from our findings that the metabolism of photosynthesized $\mathrm{D}_{3}$ to $1 \alpha, 25(\mathrm{OH})_{2} \mathrm{D}_{3}$ in keratinocytes is obviously catalyzed by $\mathrm{P} 450$ mixed function oxidases. Our findings demonstrate the UVB-triggered conversion of 7-DHC to substantial amounts of $1 \alpha, 25(\mathrm{OH})_{2} \mathrm{D}_{3}$ in $\mathrm{HaCaT}$ keratinocytes. In vivo experiments using the microdialysis technique demonstrated cutaneous generation of $1 \alpha, 25(\mathrm{OH})_{2} \mathrm{D}_{3} \quad 12-18 \mathrm{~h}$ after the skin was UVB irradiated at $300 \mathrm{~nm}$ in therapeutical doses. These findings are of potential importance for the proliferation, differentiation and apoptosis of keratinocytes as well as immunsuppression in skin under influence of UVB. Also, one could speculate whether the therapeutical effect of UVB in hyperproliferative skin diseases such as psoriasis can be partially attributed to the action of epidermally synthesized calcitriol. 


\section{References}

1 Holick MF, MacLaughlin JA, Clark MB, Holick SA, Potts, JT: Photosynthesis of of previtamin $\mathrm{D}_{3}$ in human skin and the physiologic consequences. Science 1980;210:203-205.

2 Ponchon G, Kennan AL, DeLuca HF: Activation of vitamin $\mathrm{D}$ by the liver. Clin Invest 1969;48:2032-2037.

3 Horsting M, DeLuca HF: In vitro production of 25-hydroxycholecalciferol. Biochem Biophys Res Comm 1969;36:251-256.

4 Holick MF, Schnoes HK, DeLuca HF: Identification of 1,25-dihydroxycholecalciferol, a form of vitamin $\mathrm{D}_{3}$ metabolically active in the intestine. Proc Natl Acad Sci USA 1971;68. 177-181.

5 Lawson DE, Fraser DR, Kodicek E, Morris HR, Williams DH: Identification of 1,25-dihydroxycholecalciferol, a new kidney hormone controlling calcium metabolism. Nature 1971; 230:228-230.
6 Matsumoto K, Hashimoto K, Nishida Y, Hashiro M, Yoshikawa K: Growth-inhibitory effects of 1,25-dihydroxyvitamin $\mathrm{D}_{3}$ on normal human keratinocytes cultured in serum-free medium. Biochem Biophys Res Commun 1990;166:916-923.

7 Hosomi J, Hosoi J, Abe E, Suda T, Kuroki T: Regulation of terminal differentiation of cultured mouse epidermal cells by $1 \alpha, 25$-dihydroxyvitamin $\mathrm{D}_{3}$. Endocrinology 1983;113: 1950-1957.

8 Smith EL, Walworth NC, Holick MF: Effect of 1 $\alpha, 25$-dihydroxyvitamin $\mathrm{D}_{3}$ on the morphologic and biochemical differentiation of cultured human epidermal keratinocytes grown in serum-free conditions. J Invest Dermatol 1986; 86:709-714.

9 Bikle DD, Nemanic MK, Elias P: 1,25-Dihydroxyvitamin $\mathrm{D}_{3}$ production by human keratinocytes. J Clin Invest 1986;78:557-566.

10 Bikle DD, Halloran BP, Riviere JE: Production of 1,25-dihydroxyvitamin $\mathrm{D}_{3}$ by perfused pig skin. J Invest Dermatol 1986;102:796-798.
11 Lehmann B, Pietzsch J, Kämpf A, Meurer M: Human keratinocyte line $\mathrm{HaCaT}$ metabolizes vitamin $\mathrm{D}_{3}$ and $1 \alpha$-hydroxyvitamin $\mathrm{D}_{3}$ to 1 $\alpha, 25$-dihydroxyvitamin $\mathrm{D}_{3}$. J Dermatol Sci 1998;18:118-127.

12 Lehmann B, Rudolph T, Pietzsch J, Meurer M Conversion of vitamin $\mathrm{D}_{3}$ to $1 \alpha, 25$-dihydroxyvitamin $\mathrm{D}_{3}$ in human skin equivalents. Exp Dermatol 2000;9:97-103.

13 Wilkinson CF, Hetnarski K, Cantwell GP, DiCarlo FJ: Structure-activity relationships in the effects of 1-alkylimidazoles on microsomal oxidation in vitro and in vivo. Biochem Pharmacol 1974; 23:2377-2386.

14 Sietsema WK, DeLuca HF: Retinoic acid 5,6epoxidase: properties and biological significance. J Biol Chem 1982;257:4265.

15 Hollis BW: Assay of circulating 1,25-dihydroxyvitamin D involving a novel single-cartridge extraction and purification procedure. Clin Chem 1986;32:2060-2063. 